\title{
The Impact of Small Field's Off-Set on Output Factor in Intensity Modulated Radiation Treatment
}

\author{
Hulya Ozdemir ${ }^{1,2}$, Nina Tuncel ${ }^{1 *}$, Adem Unal Kizildag3 \\ ${ }^{1}$ Physics Department, Faculty of Science, Akdeniz University, Antalya, Turkey \\ ${ }^{2}$ Gammaray Private Health Services, Istanbul, Turkey \\ ${ }^{3}$ Elekta Medical Systems, Istanbul, Turkey \\ Email: *ninatuncel@akdeniz.edu.tr
}

How to cite this paper: Ozdemir, H., Tuncel, N. and Kizildag, A.U. (2017) The Impact of Small Field's Off-Set on Output Factor in Intensity Modulated Radiation Treatment. International Journal of Medical Physics, Clinical Engineering and Radiation Oncology, 6, 433-444.

https://doi.org/10.4236/ijmpcero.2017.64039

Received: October 22, 2017

Accepted: November 20, 2017

Published: November 23, 2017

Copyright (c) 2017 by authors and Scientific Research Publishing Inc. This work is licensed under the Creative Commons Attribution International License (CC BY 4.0).

http://creativecommons.org/licenses/by/4.0/

\section{(c) (i) Open Access}

\begin{abstract}
In intensity modulated radiation treatment (IMRT) planning, the use of asymmetrically collimated fields that are placed on central axis or its off-set is mostly required. Output is the main topic discussed today for extremely small and/or severe irregularly shaped fields. The air scatter data are involved directly or indirectly in obtaining the output. Despite the fact that extensive data have been published in many studies to provide a guide on the magnitude of output factor for clinical accelerators, there are very few data reviewed about output factor in-air or phantom for off-set fields. This study was aimed to investigate the impact of these conditions for small fields. This study was conducted in Elekta Synergy linear accelerator which produces $6 \mathrm{MV}$ X-ray energy. The in-air output factor $\left(\mathrm{S}_{\mathrm{c}}\right)$ has been measured by CC04 ion chamber with brass-alloy "build-up" cap and Dose-1 electrometer, and the total output $\left(\mathrm{S}_{\mathrm{cp}}\right)$ measurements were carried on at dose maximum depth in phantom by the same chamber and Thermoluminescence dosimeter (TLD) for $1-10 \mathrm{~cm}^{2}$ fields. The all measurements at center of isocenter and off-set fields at three directions (X2, Y1, Diagonal) were done. By decreasing field size from 10 to $2 \mathrm{~cm}^{2}$ at isocenter, the Sc value using CC04 was decreased to $5.4 \%$ and $S_{c p}$ using CC04 and TLD to $14.5 \%$ and $11 \%$ respectively. By increasing off-set value, the $S_{c}$ and $S_{c p}$ values were increased in all directions comparing to central fields. The maximum increase was obtained in $\mathrm{Y} 1$ direction for $\mathrm{S}_{\mathrm{c}}$ and $\mathrm{S}_{\mathrm{cp}}$. TLD results for $\mathrm{S}_{\mathrm{cp}}$ is slightly higher than $\mathrm{CC} 04$. The dosimetric properties of small fields and their off-set should be evaluated and modelled appropriately in the treatment planning system to ensure accurate dose calculation in Intensity Modulated Radiation Treatment.
\end{abstract}




\section{Keywords}

Small Field, Off-Set Fields, Total Output Factor, In-Air Output Factor, Intensity Modulated Radiation Treatment

\section{Introduction}

Generally, in radiation therapy (RT), the reliability of treatment planning system that based on factors or model is affected by many factors. These may include such phenomena as scattered photons by structures in the linear accelerator head (head-scatter), backs catered photons and electrons into the monitor chamber (monitor backscatter), and the partially obscuring of the X-ray source by the collimators (source-obscuring effect) especially in very small fields [1]. Various sources of head-scatter, which include in the primary collimator, the flattening filter, the secondary collimators, the monitor chamber and a wedge, if used, have been considered [2] [3] [4]. The size of collimator aperture describes the X-ray output and multi-leaf collimator (MLC), which has a critical role for shaping the radiation field.

The concept of output for a field size describes the absorbed dose for X-ray produced by linear accelerators (LINAC). The in-air X-ray scatter component composes the main part of output. But in dosimetry procedure of RT, this concept refers to absorbed dose to medium or water. It could be claimed that the medium (water or phantom) scatter contains a minor part of output. Output is the main topic discussed today for extremely small and/or severe irregularly shaped fields [5]. The air scatter data are involved directly or indirectly in obtaining the output. Generally, the collimator arrangement of any LINAC consists of fixed and movable structures. The Flattening Filter which constitutes one of the fixed structures in any LINAC is placed between the primary collimator and the monitor chamber, and its main role is to make the photon beam dose distribution uniform at a reference depth [4]. The X-Y jaws and MLC with unidirectional motion that play a major role in field shaping constitute the moving structures of LINACs. The concept of in-air output ratio [6] [7] [8] [9] is characterized by the variation in the incident photon fluence per monitor unit according to collimator settings, which is known as collimator scatter factor [10] or head scatter factor $\left(S_{c}\right)$ for photon [11] [12]. The "In-air output factor" that contains the latest two definitions is commonly used and usually symbolized as $S_{c}$. It includes the source-obscuring effect, the head-scatter and the monitor backscatter effect. Many recommendations are given for using small size detector for fields smaller than $3 \times 3 \mathrm{~cm}^{2}$, because significant differences can be found among using different detectors. The underestimation of output factors due to the increase of lateral electron disequilibrium and the volume effect of detectors is expected [13] [14] [15].

In intensity modulated radiation treatment (IMRT) planning, the use of asym- 
metrically collimated fields that is placed on central axis or its off-set is mostly required. Generally, the initial part of IMRT dose calculations is an energy fluence optimization that is directly related to Sc measurements. The head scatter factor (in-air output ratio, Sc) is defined as the ratio of primary collision water kerma in air per monitor units (MU) at isocentric distance $(100 \mathrm{~cm})$ for a given field setting to that of a reference $10 \times 10 \mathrm{~cm}^{2}$ field. Accurate determination of $\mathrm{Sc}$ for IMRT is much more challenging, where extremely small and/or severe irregularly shaped fields are more commonly used [5]. The Sc emphasizing a component of the output concept varies with field size at related photon energy.

The treatment planning system's software that could calculate dose distributions for more complex treatment containing configurations is directly related to head scatter modelling, output factor determination, and monitor unit calculations, respectively. The applied algorithms are based on either empirical methods, analytical models, or a combination of both [16]. The extensive data have been published in many studies to provide a guide on the magnitude of output factor for clinical accelerators. But, there are very few data have been reviewed about output factor in-air or phantom for off-set fields [17]. This study was aimed to investigate the impact of off-set conditions on in-air and total output factor for small fields in IMRT.

\section{Methods and Materials}

\subsection{Dosimetric Equipment and Processes}

This study was conducted in Elekta Synergy linear accelerator that produced 6 MV X-ray energy. The head diagram of Elekta (TM) linear accelerator (Elekta AB, Stockholm, Sweden) is equipped by MLC with $1 \mathrm{~cm}$ width leaf for providing shaped fields (Figure 1) and also small fields for performing step and shot intensity modulated radiation treatments. Each leaf can travel $12.5 \mathrm{~cm}$ over the beam central axis regarding shifting to $\times 2$ axis direction. And it is contained flattening filter.

The small volume compact ionization chamber was preferred to use in small fields and high dose rates measurements.

The high spatial resolution cylindrical ion chamber (Figure 2), CC04 (IBA, GmBH, Scanditronix Wellhofer, Germany) with cavity volume of $0.04 \mathrm{~cm}^{3}$ was used for measurements [19].

The $S_{c}$ measurements were performed by this chamber with brass-alloy "build-up" cap that designed for $6 \mathrm{MV}$ X-ray energy and Dose-1 electrometer. This "build-up" cap was made of brass alloy (Copper, Nickel, Zinc, Lead, Tin, Manganese and Iron) with $8.62 \mathrm{~g} / \mathrm{cm}^{3}$ density. Its outer diameter is $13.6 \mathrm{~mm}$ with $4.4 \mathrm{~mm}$ wall thickness.

The $\mathrm{S}_{\mathrm{cp}}$ measurements at dose maximum depth $(1.6 \mathrm{~cm})$ in RW3 solid-water phantom (IBA, GmBH, Germany) by the same ion chamber and electrometer were carried on for $1 \times 1-10 \times 10 \mathrm{~cm}^{2}$ fields. This arrangement was used for $S_{c p}$ 


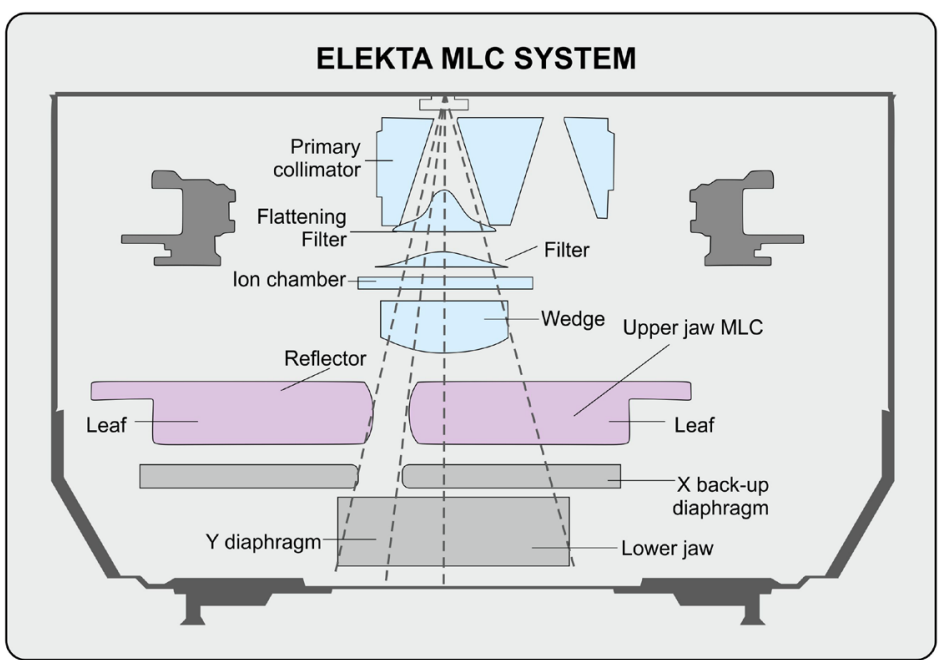

Figure 1. The head diagram of Elekta (TM) Linear accelerator head [18].

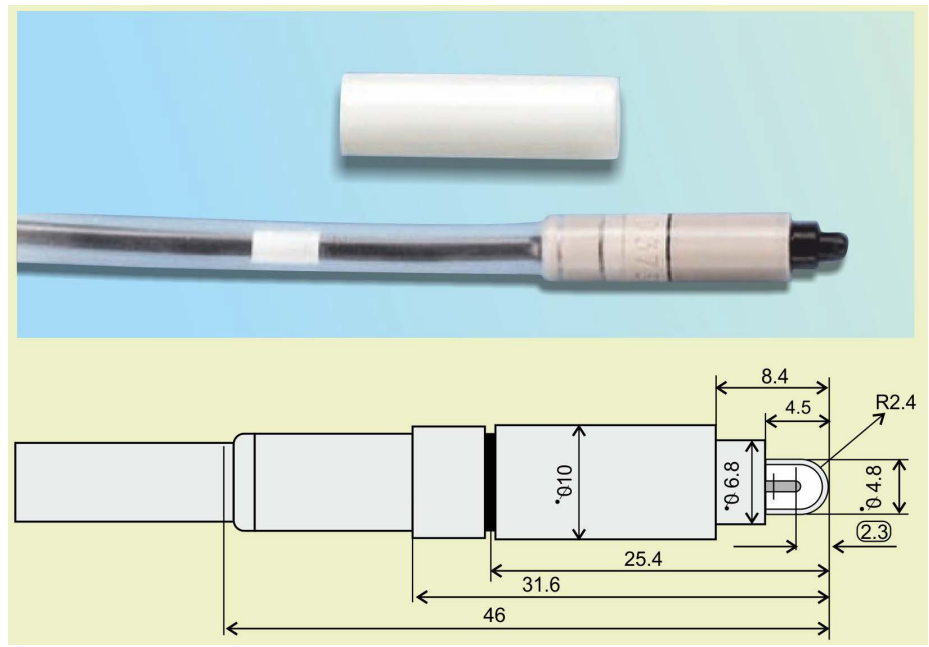

(a)

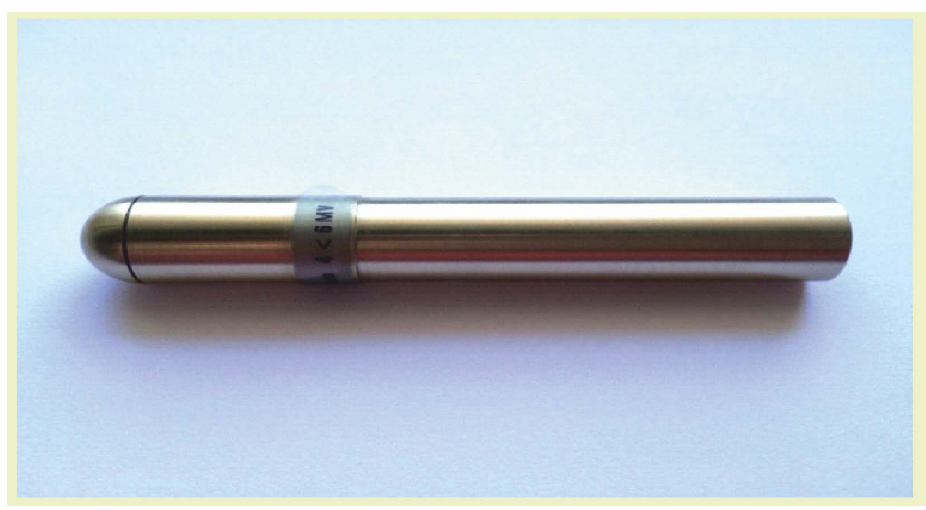

(b)

Figure 2. (a) Scanditronix-Wellhöfer CC04 compact ion chamber and its diagram; (b) Brass-alloy "build-up" cap [19].

measurement by Thermoluminescence dosimeter (TLD). LiF-100 (LiF: Mg, Ti) disc-shaped crystals have $4.5 \mathrm{~mm}$ in diameter, $0.9 \mathrm{~mm}$ in thickness (MTS-N Pol- 
and). The two TLD discs were embedded in a RW3 solid-water phantom plate for obtaining adequate measurement depth. RADOS RE-2000RT (RadRpo Int. GmbH Germany) with RADOS TLD Server software was used for TLD readings. In this study, TLDs' with $\pm 3 \%$ sensitivity were selected. TL-count conversion to dose was done for $6 \mathrm{MV}$ energy using the dose of $10 \times 10 \mathrm{~cm}^{2}$ field, SSD $=100 \mathrm{~cm}$ at $\mathrm{d}_{\text {Dmax}}$.

\subsection{In-Air and Total Output Factor Measurements for Central Fields and Off-Set Fields}

Computer-aided water phantom was used to minimize the displacement error and the geometric shift for ion chamber matching with isocenter for $\mathrm{S}_{\mathrm{c}}$. The chamber with brass-alloy cap that paralleled to beam was placed in the empty phantom at the center of field (Figure 3). The source and tip of "build-up" cap distance was set to $100 \mathrm{~cm}$. The output measurements per $100 \mathrm{MU}$ for $1 \times 1,2 \times 2,3$ $\times 3,4 \times 4,5 \times 5,6 \times 6$ and $10 \times 10 \mathrm{~cm}^{2}$ fields were performed. The corrected for both pressure and temperature readings by CC04 chamber with Dose-1 electrometer were obtained as a Gray (Gy).

The output measurements for off-set fields called OSF procedure was the same as $S_{c}$ in-air output factor measurement while the field location was placed on centre of off-set fields at three directions (X2, Y1 and Diagonal) (Figure 4). The applicable off-set conditions at each direction for $S_{c}$ measurements were given by “ $\sqrt{ }$ " symbol that inserted in Table 1.

The $S_{c p}$ measurements at dose maximum depth $(1.6 \mathrm{~cm})$ in RW3 phantom using the same chamber and TLD were carried on fields that mentioned above for $S_{c p}$. The source-surface distance was set to $100 \mathrm{~cm}$ and irradiation of $100 \mathrm{MU}$ per field was performed. The total output measurements for OSFs procedure was the same as $S_{c p}$ total output factor measurement while the field location was placed on centre of OSFs at three directions (X2, Y1 and Diagonal). This measurement was done by both CC04 ion chamber and TLD pairs. The applicable OSF conditions at each direction for $\mathrm{S}_{\mathrm{cp}}$ measurements were given by “‘” symbol that inserted in Table 1.

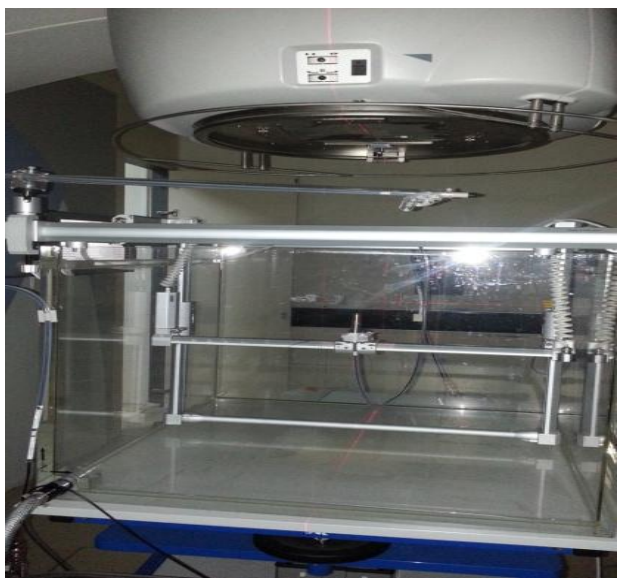

Figure 3. The in-air output measurement set-up. 


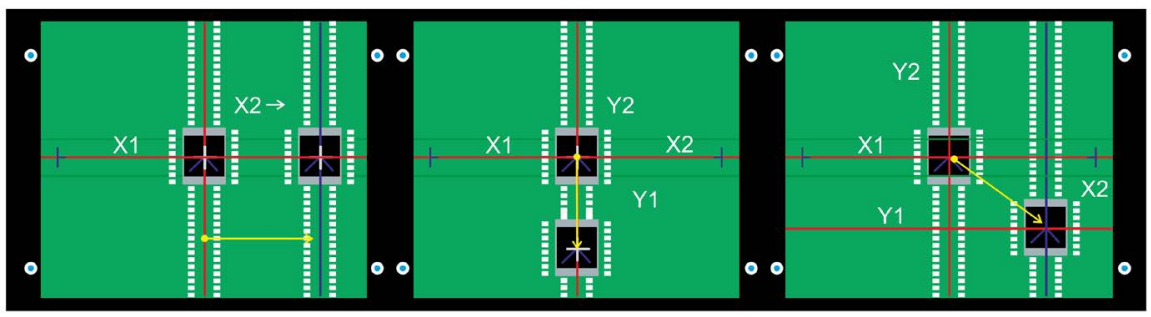

Figure 4. The field locations depend on off-set fields at (a) X2; (b) Y1; and (c) Diagonal directions.

Table 1. The $\mathrm{S}_{\mathrm{c}}$ and $\mathrm{S}_{\mathrm{cp}}$ measurement conditions: off-set value along (a) X2; (b) Y1; and (c) Diagonal direction for each field.

(a)

\begin{tabular}{ccccccccc}
\hline \multirow{2}{*}{ Field $\left(\mathrm{cm}^{2}\right)$} & \multicolumn{8}{c}{ (a) Off-Set Value along X2 Direction $(\mathrm{cm})$} \\
\cline { 2 - 8 } & 0 & 2 & 4 & 6 & 8 & 10 & 12 & 14 \\
\hline $10 \times 10$ & $\sqrt{ }, *$ & $\sqrt{ }$ & $\sqrt{ }$ & $\sqrt{ }, *$ & $\sqrt{ }$ & $\sqrt{ }$ & $\sqrt{ }, *$ & $\sqrt{ }, *$ \\
$6 \times 6$ & $\sqrt{ }, *$ & $\sqrt{ }$ & $\sqrt{ }$ & $\sqrt{ }, *$ & $\sqrt{ }$ & $\sqrt{ }$ & $\sqrt{ }, *$ & $\sqrt{ }, *$ \\
$5 \times 5$ & $\sqrt{ }, *$ & - & - & - & - & - & - & - \\
$4 \times 4$ & $\sqrt{ }, *$ & $\sqrt{ }$ & & $\sqrt{ }, *$ & & $\sqrt{ }$ & $\sqrt{ }, *$ & $\sqrt{ }, *$ \\
$3 \times 3$ & $\sqrt{ }, *$ & - & - & - & - & - & - & - \\
$2 \times 2$ & $\sqrt{ }, *$ & $\sqrt{ }$ & - & $\sqrt{ }, *$ & - & $\sqrt{ }, *$ & $\sqrt{ }, *$ & - \\
$1 \times 1$ & $\sqrt{ }, *$ & - & - &,$- *$ & - &,$- *$ &,$- *$ & - \\
\hline
\end{tabular}

(b)

\begin{tabular}{ccccccccc}
\hline \multirow{2}{*}{ Field $\left(\mathrm{cm}^{2}\right)$} & \multicolumn{7}{c}{ (b) Off-Set Value along Y1 Direction $(\mathrm{cm})$} \\
\cline { 2 - 8 } & 0 & 2 & 4 & 6 & 8 & 10 & 12 & 14 \\
\hline $10 \times 10$ & $\sqrt{ }, *$ & $\sqrt{ }$ & $\sqrt{ }$ & $\sqrt{ }, *$ & $\sqrt{ }$ & $\sqrt{ }$ &,$- *$ & $\sqrt{ }, *$ \\
$6 \times 6$ & $\sqrt{ }, *$ & $\sqrt{ }$ & - & $\sqrt{ }, *$ & - & $\sqrt{ }, *$ & $\sqrt{ }, *$ & $\sqrt{ }, *$ \\
$5 \times 5$ & $\sqrt{ }, *$ & - & - & - & - & - & - & - \\
$4 \times 4$ & $\sqrt{ }, *$ & $\sqrt{ }$ & - & $\sqrt{ }, *$ & - & $\sqrt{ }$ & $\sqrt{ }, *$ & $\sqrt{ }, *$ \\
$3 \times 3$ & $\sqrt{ }, *$ & - & - & - & - & - & - & - \\
$2 \times 2$ & $\sqrt{ }, *$ & $\sqrt{ }$ & - & $\sqrt{ }, *$ & - & $\sqrt{ }, *$ & $\sqrt{ }, *$ & $\sqrt{ }, *$ \\
$1 \times 1$ & $\sqrt{ }, *$ & - & - & - & - & - & - & - \\
\hline
\end{tabular}

(c)

\begin{tabular}{ccccccccc}
\hline \multirow{2}{*}{ Field $\left(\mathrm{cm}^{2}\right)$} & \multicolumn{7}{c}{ (c) Off-Set Value along Diagonal Direction $(\mathrm{cm})$} \\
\cline { 2 - 8 } & 0 & 2 & 4 & 6 & 8 & 10 & 12 & 14 \\
\hline $10 \times 10$ & $\sqrt{ }, *$ & $\sqrt{ }$ & - & $\sqrt{ }, *$ & - & $\sqrt{ }$ & $\sqrt{ }, *$ & - \\
$6 \times 6$ & $\sqrt{ }, *$ & $\sqrt{ }$ & - & $\sqrt{ }, *$ & - & $\sqrt{ }$ & $\sqrt{ }, *$ & - \\
$5 \times 5$ & $\sqrt{ }, *$ & - & - & - & - & - & - & - \\
$4 \times 4$ & $\sqrt{ }, *$ & $\sqrt{ }$ & - & $\sqrt{ }, *$ & - & $\sqrt{ }$ & $\sqrt{ }$ & - \\
$3 \times 3$ & $\sqrt{ }, *$ & - & - & - & - & - & - & - \\
$2 \times 2$ & $\sqrt{ }, *$ & - & - & - & - & - & - & - \\
$1 \times 1$ & $\sqrt{ }, *$ & - & - & - & - & - & - & - \\
\hline
\end{tabular}




\section{Results}

This study was conducted in Elekta Synergy linear accelerator that produced 6 MV X-ray energy. Before measurements, the linear accelerator was calibrated to deliver $1 \mathrm{cGy} / \mathrm{MU}$ for $10 \times 10 \mathrm{~cm}^{2}$ at $\mathrm{d}_{\mathrm{Dmax}}$ and $100 \mathrm{~cm} \mathrm{SSD}$. All measurement results were obtained by applying $100 \mathrm{MU}$ per fields. The geometric uncertainty related to field aperture arrangement in LINAC and detector position in water phantom were less than $1 \mathrm{~mm}$ totally.

\subsection{In-Air and Total Output Factor Measurements for Central Fields}

The central field in-air output measurements per $100 \mathrm{MU}$ for $1 \times 1,2 \times 2,3 \times 3$, $4 \times 4,5 \times 5,6 \times 6$ and $10 \times 10 \mathrm{~cm}^{2}$ fields were performed and normalized to $10 \times$ $10 \mathrm{~cm}^{2}$ reference field for $S_{c}$. Generally, by decreasing field size from $10 \times 10$ to 1 $\times 1 \mathrm{~cm}^{2}$ the $S_{\mathrm{c}}$ value decreased. While field size changing from 10 to $2 \mathrm{~cm}^{2}$ this reducing rate was $5.4 \%$, and by adding $1 \times 1 \mathrm{~cm}^{2}$ field to this range it was dramatically drop to $12.5 \%$. $\mathrm{S}_{c}$, in-air output, values for central fields were shown in the first row (off-set $=0$ ) of Figure 5 .

The results for total output factor by CC04 and TLD were shown in the first column (off-set $=0$ ) of Figure 6(a). By decreasing field size from 10 to $2 \mathrm{~cm}^{2}$ the $\mathrm{S}_{\mathrm{cp}}$ value was decreased by using both detectors. The decreasing ratio in the results by CC04 and TLD were reached to $14.5 \%$ and $11 \%$ respectively. When including $1 \times 1 \mathrm{~cm}^{2}$ field to this range the discrepancy between CC04 and TLD results was seen as $58.5 \%$ and $27.8 \%$, respectively.

The output factors measured by TLD and CC04 were comparable and showed close agreement with each other regarding to field sizes up to $2 \times 2 \mathrm{~cm}^{2}$. While for fields smaller than $2 \times 2 \mathrm{~cm}^{2}$ these results got deviations (Figure 6(a)).

\subsection{In-Air and Total Output Factor Measurements for Off-Set Fields}

The in-air output measurement values for different off-set distances and indicated fields were obtained (Table 1). For calculating $S_{c}$ factor for them, the in-air

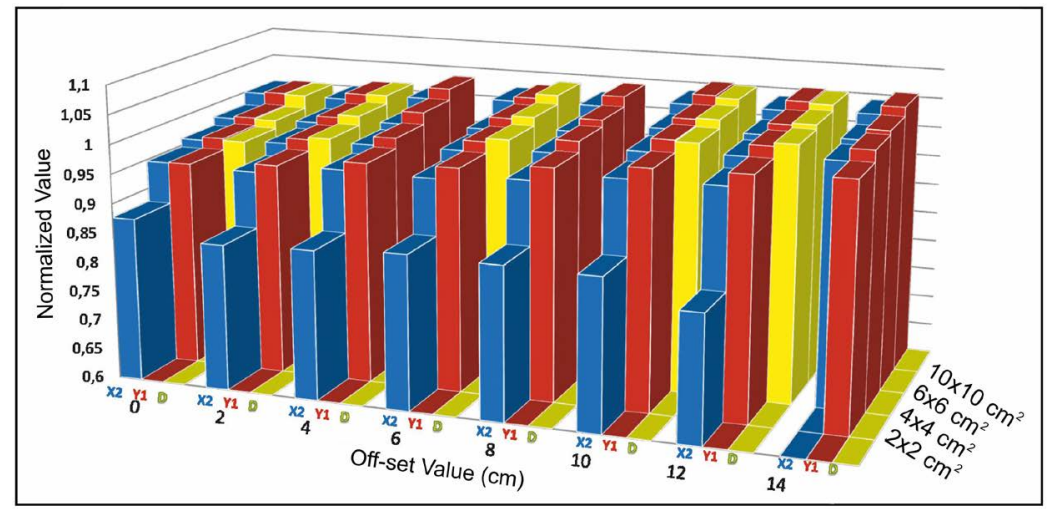

Figure 5. The normalized $S_{c}$ values according field size and its off-set value on each X2, Y1 and diagonal directions. 


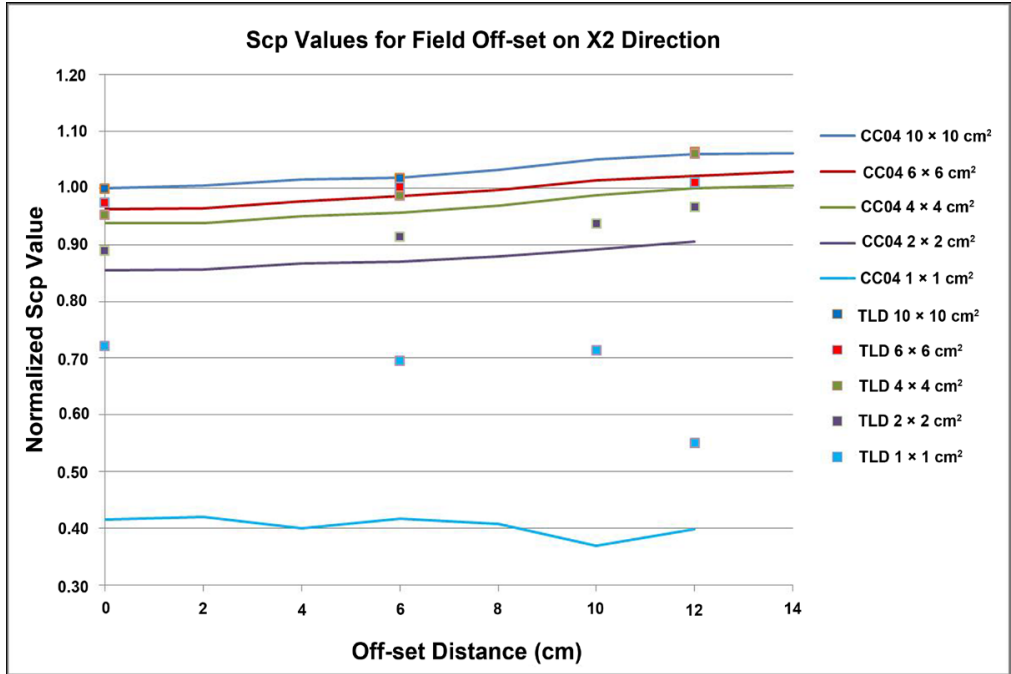

(a)

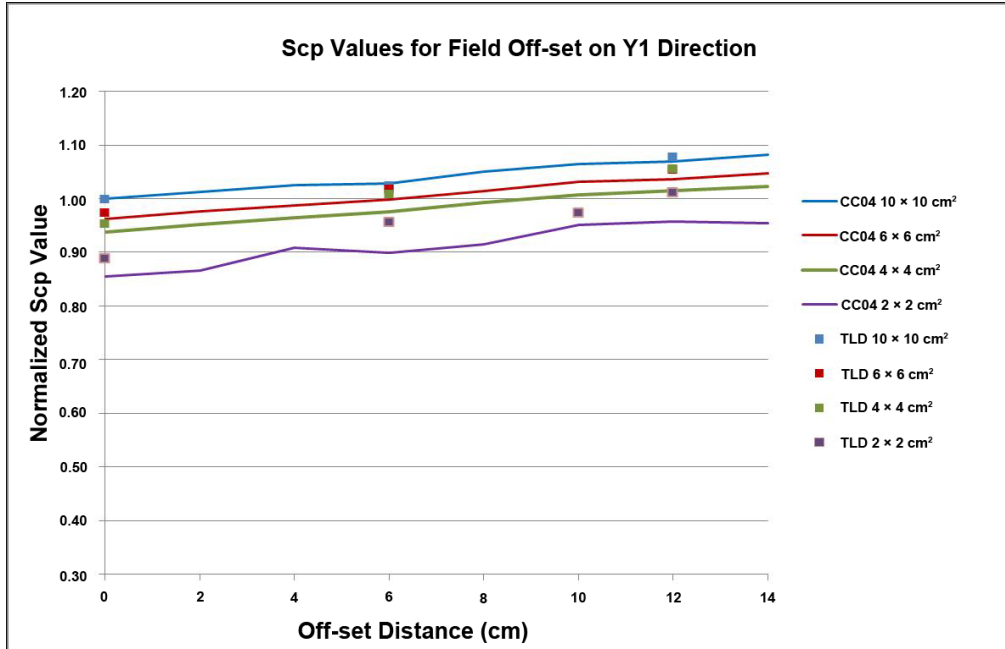

(b)

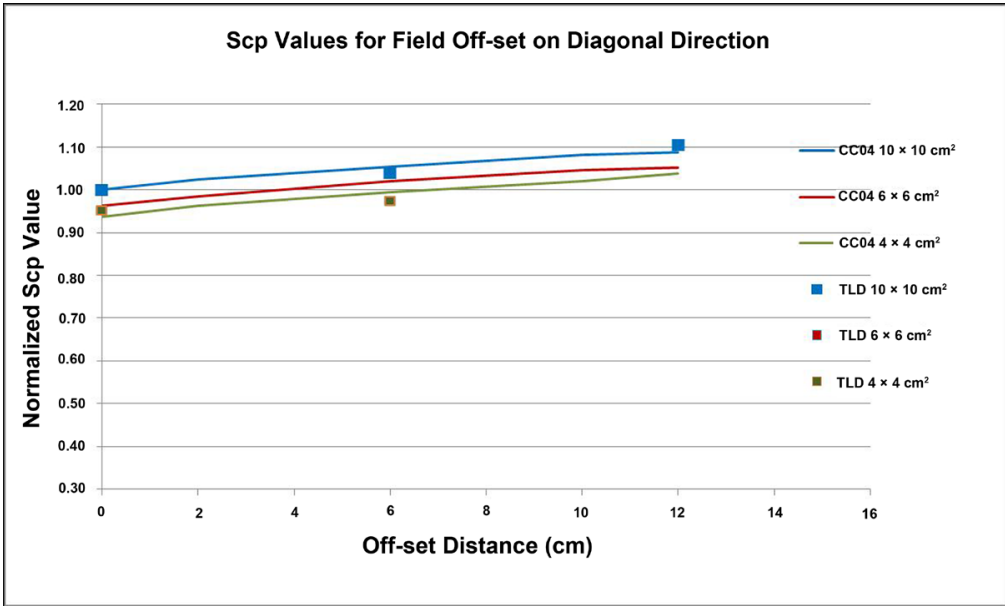

(c)

Figure 6. The normalized $S_{c p}$ values were obtained from CC04 ion chamber and TLD according field size and its off-set distance on each (a) X2; (b) Y1; and (c) Diagonal directions. 
output of $10 \times 10 \mathrm{~cm}^{2}$ field that placed on central axis was used. The normalized $\mathrm{S}_{\mathrm{c}}$ values according to $10 \times 10 \mathrm{~cm}^{2}$ for three directions $\mathrm{X} 2$, Y1 and Diagonal are shown in Figure 5. By increasing off-set value on any direction for each field, the $S_{c}$ value was increased (excluding $1 \times 1 \mathrm{~cm}^{2}$ field size). For example, the $S_{c}$ value for $4 \times 4 \mathrm{~cm}^{2}$ field was raised to $5.9 \%, 5.6 \%$ and $3 \%$ on X2, Y1 and Diagonal direction, respectively. The maximum increase in $\mathrm{S}_{\mathrm{c}}$ was seen on the $\mathrm{Y} 1 \mathrm{Direc}-$ tion when all results were evaluated.

The total output measurement values using CC04 and TLD for off-set fields was obtained and the total output of $10 \times 10 \mathrm{~cm}^{2}$ field that placed on central axis was used for calculating $S_{\mathrm{cp}}$ factor. The normalized $S_{\mathrm{cp}}$ values according to $10 \times 10$ $\mathrm{cm}^{2}$ for three directions X2, Y1 and Diagonal are shown in Figures 6(a)-(c) respectively. By increasing off-set value on any direction for each identified fields the $S_{c p}$ value was increased for both detectors (excluding $1 \times 1 \mathrm{~cm}^{2}$ field). For example, the $\mathrm{S}_{\mathrm{cp}}$ values by CC04 for $4 \times 4 \mathrm{~cm}^{2}$ field was raised to $7.2 \%, 11.6 \%$ and $10.7 \%$ on $\mathrm{X} 2$, Y1 and Diagonal direction, respectively. These values were $11.2 \%$, $13.7 \%$ and $10.8 \%$ respectively from results by using TLDs. Total output factors measured by TLD showed close agreement with those measured using the ion chamber for field sizes of $4 \times 4 \mathrm{~cm}^{2}$ and above. It is recognized that TLD's were more sensitive for small fields especially $1 \times 1 \mathrm{~cm}^{2}$ and $2 \times 2 \mathrm{~cm}^{2}$ in off-set measurements compared to CC04. The maximum increase in $\mathrm{S}_{\mathrm{cp}}$ was seen on the $\mathrm{Y} 1$ Direction, when all results were evaluated.

\section{Discussion}

Khan et al. [10] has declared that in the case of static MLC in conventional radiotherapy, $\mathrm{S}_{\mathrm{c}}$ for a given jaw opening is affected very little by the MLC setting for fields larger than $4 \times 4 \mathrm{~cm}^{2}$. On the other hand, when the MLC aperture is reduced to $1 \times 1 \mathrm{~cm}^{2}$ field this factor drops to $5 \%$. The $S_{c}$ characteristics which obtained from this study were consistent with findings of Zhu et al. [12], Jaffray et al. [2] and Sharpe et al. [3]. The $S_{c}$ value for square fields of sides $10^{-1} \mathrm{~cm}$ in many studies demonstrated a decreasing with different ranges related to energy, these were 0.823 for $10 \mathrm{MV}$ [19] and 0.91 for $6 \mathrm{MV}$ X-ray energy [20]. When the field size decreased, the direct-beam source was partially blocked, so the number of direct-beam (primary photons) reaching to the measure-point was reduced and Sc value decreased [21]. However, at field sizes smaller than $2 \times 2 \mathrm{~cm}^{2}$ the direct beam source was shielded by the collimating structures and source occlusion became important. So, the sharply decrease of Sc was seen at $1 \times 1 \mathrm{~cm}^{2}$.

Das et al. showed that the output factor for small fields at $6 \mathrm{MV}$ X-ray energy was strongly depend on detector type and a rapid drop in output with a certain detector was observed when the field size was decreased especially including $1 \times$ $1 \mathrm{~cm}^{2}$ field [22] [23]. Also, Cranmer-Sargison et al. found the same measurement results using different ion chamber [14]. Because of the volume effect and water-equivalent property of TLD, the results obtained from them were more reliable and higher then CC04 ion chamber results (Figure 6(a)). 
Shih et al. proposed a method for the calculation of head scatter or in-air output factor for an arbitrary jaw setting. They found that the head scatter factors at isocenter for asymmetric fields are lower than for the same jaw setting that placed at centre of field by up to $4 \%$ [24]. It can be recognized that the off-set of fields that generally used in creating of asymmetric fields by collimator settings also affect the $S_{c}$ value.

There is a quite little information about evaluations regarding off-set of fields and their $\mathrm{S}_{\mathrm{cp}}$ value. Only one study contained the evaluation of $4 \mathrm{~cm}$ shift on leaf axis for square fields from 0.5 up to $10 \mathrm{~cm}^{2}$. The $S_{c p}$ ratio regarding off-set field to no off-set field did not show any fluctuation from 10 to $4 \mathrm{~cm}^{2}$ fields while by decreasing of field size to $0.5 \mathrm{~cm}$, this ratio dropped to $13 \%$ in $6 \mathrm{MV}$ X-ray energy [25]. When the results of this study were compared to our results, the same outcomes were driven for shifts up to $6 \mathrm{~cm}$ at each direction for fields larger than $4 \mathrm{~cm}^{2}$. For larger off-set or shift values on this range of fields $\mathrm{S}_{\mathrm{cp}}$ ratio raised to maximum $10 \%$. On the other hand, for $4 \mathrm{~cm}^{2}$ and $2 \mathrm{~cm}^{2}$ fields the large off-set distance caused increasing slightly higher than $10 \%$. An additional comparison could be made between the results regarding to use of the different detector types. The difference in the active volumes of the detectors used in this study represents the most likely cause of large differing in $\mathrm{S}_{\mathrm{cp}}$ values especially for fields smaller than $4 \mathrm{~cm}^{2}$.

\section{Conclusions}

This study was focused on the impact of off-set conditions of in-air and total output factor for $1-10 \mathrm{~cm}^{2}$ radiation fields at $6 \mathrm{MV} \mathrm{X}$-ray photon energy by a linear accelerator with collimation device equipped by $1 \mathrm{~cm}$ leaf width. By increasing off-set distance, the $S_{c}$ and $S_{c p}$ values were increased for any related fields regarding shift at all directions comparing to central fields. There are some commencements related to this matter: the particular configuration of a LINAC head and collimation device, the flattening filter and its geometry and etc. The contribution of scattered photons from the primary collimator was larger than that of the flattening filter, and backscattered particles were affected not only by the upper jaw but also the lower jaw. Therefore, the low secondary filter was correctly modelled, because the design of this filter plays a role in the variation of the accelerator output as a function of the off-set fields. In this case, it is considered that the increase of $S_{c}$ and $S_{c p}$ values is due to the breakdown of the homogeneity at the off-set fields depending on the flattening filter design. So, the photons that arrived to the distal fields are supposed to pass from the edge of the flattening filter intensely and in the average, more energetic. Based on this fact, the $S_{c}$ and $S_{c p}$ values related to off-set fields should be assessed during TPS quality control processes.

Also, the farther works need to perform for each LINAC head design to obtain additional factor on regard to off-set distance for $S_{c}$ and $S_{c p}$ of small fields that hugely used in IMRT treatment plans. 
There are now an increasing number of innovated detectors for small field dosimetry as miniature ionization chambers, diodes, synthetic diamonds, and plastic scintillators that these will seem to lead a solution for dosimetry of very small field as well dosimetry of their off-set position.

In conclusion, the dosimetric properties of small fields and their off-set should be evaluated and modelled appropriately in the treatment planning system to ensure accurate dose calculation in Intensity Modulated Radiation Treatment.

\section{Acknowledgements}

This work was supported by Akdeniz University Research Project Coordination Unit (Project No. 2014.02.0121.008). It was carried on Radiotherapy Centre, Denizli State Hospital, Turkey and the authors would like to thank the members of this centre.

\section{References}

[1] Zhu, T.C. and Bjärngard, B.E. (1995) The Fraction of Photons Undergoing Head Scatter in X-Ray Beams. Physics in Medicine and Biology, 40, 1127-1134. https://doi.org/10.1088/0031-9155/40/6/011

[2] Jaffray, D.A., Battista, J.J., Fenster, A. and Munro, P. (1993) X-Ray Sources of Medical Linear Accelerators: Focal and Extra-Focal Radiation. Medical Physics, 20, 1417-1427. https://doi.org/10.1118/1.597106

[3] Sharpe, M.B., Jaffray, D.A., Battista, J.J. and Munro, P. (1995) Extrafocal Radiation: A Unified Approach to the Prediction of Beam Penumbra and Output Factors for Megavoltage X-Ray Beams. Medical Physics, 22, 2065-2074.

https://doi.org/10.1118/1.597648

[4] Sharma, S.D. (2011) Unflattened Photon Beams from The Standard Flattening Filter Free Accelerators for Radiotherapy: Advantages, Limitations and Challenges. Medical Physics, 36, 123-125. https://doi.org/10.4103/0971-6203.83464

[5] Zhu, T.C., Ahnesjö, A., Lam, K.L., Li, X.A., Ma, C.M., Palta, J.R., Sharpe, M.B., Thomadsen, B. and Tailor, R.C. (2009) In-Air Output Ratio, Sc, for Megavoltage Photon Beams. Report of the AAPM Radiation Therapy Committee Task Group No. 74. Medical Physics, 36, 5261-5291. https://doi.org/10.1118/1.3227367

[6] Dutreix, A., Bjärngard, B.E., Bridier, A., Mijnheer, B., Shaw, J.E. and Svensson, H. (1997) Monitor Unit Calculation for High Energy Photon Beams. Physics for Clinical Radiotherapy. ESTRO Booklet No. 3. Garant, Leuve, 36 p.

[7] Young, M.E.J. (1957) Radiological Physics. 1st Edition, Academic, New York, 207 p.

[8] Holt, J.G., Laughlin, J.S. and Moroney, J.P. (1970) The Extension of The Concept of Tissue-Air Ratios TAR to High-Energy X-Ray Beams. Radiology, 96, 437-446. https://doi.org/10.1148/96.2.437

[9] Kim, S., Palta, J.R. and Zhu, T.C. (1998) A Generalized Solution for The Calculation of In-Air Output Factors in Irregular Fields. Medical Physics, 25, 1692-1701. https://doi.org/10.1118/1.598350

[10] Khan, F.M. and Gibbons, J.P. (2014) The Physics of Radiation Therapy. 5th Edition, Lippincott Williams \& Wilkins, Philadelphia, 152-153.

[11] Kase, K.R. and Svensson, G.K. (1986) Head Scatter Data for Several Linear Accelerators 4-18 MV. Medical Physics, 13, 530-532. https://doi.org/10.1118/1.595857 
[12] Tatcher, M. and Bjärngard, B.E. (1992) Head-Scatter Factors and Effective X-Ray Source Positions in A 25-MV Linear Accelerator. Medical Physics, 19, 685-686. https://doi.org/10.1118/1.596811

[13] Cranmer-Sargison, G., Weston, S., Sidhu, N.P. and Thwaites, D.I. (2011) Experimental Small Field 6 MV Output Ratio Analysis for Various Diode Detector and Accelerator Combinations. Radiotherapy and Oncology, 100, 429-435. https://doi.org/10.1016/j.radonc.2011.09.002

[14] Sharma, S.D. (2014) Challenges of Small Photon Field Dosimetry Are Still Challenging. Journal of Medical Physics, 39, 131-132. https://doi.org/10.4103/0971-6203.138998

[15] Laud, W.U. and Wong, T. (2003) The Volume Effect of Detectors in The Dosimetry of Small Fields Used in IMRT. Medical Physics, 30, 341-347. https://doi.org/10.1118/1.1544678

[16] Olofssona, J., Georgb, D. and Karlssona, M. (2003) A Widely Tested Model for Head Scatter Influence on Photon Beam Output. Radiotherapy and Oncology, 67, 225-238. https://doi.org/10.1016/S0167-8140(02)00409-7

[17] ICRU (2014) REPORT 91: Prescribing, Recording, and Reporting of Stereotactic Treatments with Small Photon Beams. Journal of the International Commission on Radiation Units and Measurements, 14, 31-53.

[18] Houdek, P.V., Vanburen, J.M. and Fayos, J.V. (1983) Dosimetry of Small Radiation Fields for 10 MV X-Rays. Medical Physics, 10, 333-336.

https://doi.org/10.1118/1.595262

[19] IBA (2011) CC04, User's Guide. http://www.iba-dosimetry.com/sites/default/files/brochure/RT-BR-E-Detectors\%20 for\%20RD\%20and\%20AD\%200211_0.pdf

[20] Thomas, S.J., Fipem, Eaton, D.J., Tudor, G.S.J. and Twyman, N.I. (2008) Equivalent Squares for Small Field Dosimetry. The British Journal of Radiology, 81, 897-901. https://doi.org/10.1259/bjr/27713136

[21] Aspradakis, M.M., Byrne, J.P., Palmans, H., Duane, S., Conway, J., Warrington, A.P. and Rosser, K. (2010) Small Field MV Photon Dosimetry. IPEM Report 103, IPEM.

[22] Das, I.J., Ding, G.X. and Ahnesjö, A. (2008) Small Fields: Nonequilibrium Radiation Dosimetry. Medical Physics, 35, 206. https://doi.org/10.1118/1.2815356

[23] Das, I.J., Morales, J. and Francescon, P. (2016) Small Field Dosimetry: What Have We Learnt? AIP Conference Proceedings, 1747, Article ID: 060001.

[24] Shih, R., Li, X.A., Chu, J.C.H. and Hsu, W.L. (1999) Calculation of Headscatter Factors at Isocenter or at Center of Field for Any Arbitrary Jaw Setting. Medical Physics, 26, 506-511. https://doi.org/10.1118/1.598549

[25] Klein, D.M., Tailor, R.C., Archambault, L., Wang, L., Therriault-Proulx, F. and Beddar, A.S. (2010) Measuring Output Factors of Small Fields Formed by Collimator Jaws and Multileaf Collimator using Plastic Scintillation Detectors. Medical Physics, 37, 5541-5549. https://doi.org/10.1118/1.3488981 